\title{
Fuentes y características del primer periodismo lojano (Ecuador): 1856-1895
}

\author{
María Luján GonzÁlez PoRTEla \\ Universidad Técnica Particular de Loja (Ecuador) \\ lujan@utpl.edu.ec \\ Rodica Nathali MOREIRA OrTEGA \\ Universidad Técnica Particular de Loja (Ecuador) \\ rodicamoreira@gmail.com \\ Antonio Checa Godoy \\ Universidad de Sevilla (España) \\ acheca@us.es
}

\begin{abstract}
Resumen
La fecundidad y riqueza del primer periodismo de Loja, en el sur de Ecuador, en el período entre 1856 y 1895, es un fenómeno no suficientemente estudiado por la historiografía existente, que si bien supone un esfuerzo de recopilación de los periódicos y revistas aparecidas en esta provincia ecuatoriana, adolecen de imprecisiones, omisiones y de un análisis muy descriptivo. Esta investigación ubica físicamente 27 periódicos y 8 revistas literarias, que constituyen casi la totalidad de publicaciones habidas, analizándolas contextualizadamente, y recopila 91 hojas volantes, como fenómeno inexplorado hasta la fecha y muy rico como expresión de la opinión ciudadana.
\end{abstract}

Palabras clave: Historia, Periodismo, Loja, siglo XIX

Sources and Characteristics of early journalism in Loja (Ecuador): 1856-1895

\begin{abstract}
The birth and richness of early journalism of Loja, southern Ecuador, during the period from 1856 to 1895 , is a phenomenon that has been insufficiently studied in the existing historiography. Although there have been efforts to study this period through the gathering and analysis of newspapers and magazines from the said province, research indicates that there are frequent inaccuracies and omissions in the data. What's more, studies carried out to date on this subject mostly lack descriptive analyses. This paper physically locates the 27 newspapers and 8 literary magazines that form almost the entire body of publications in this field. Through analysis and contextualization, it examines the usage of 91 leaflets, which serve not only as a fairly new phenomenon, but as a rich expression of public opinion.
\end{abstract}

Key Words: History, Journalism, Loja, 19th Century

\section{Referencia normalizada:}

Luján González Portela, M.; Moreira Ortega, R. N. y Checa Godoy, A. (2013) Fuentes y características del primer periodismo lojano (Ecuador): 1856-1895. Historia y Comunicación Social. Vol. 18. No Especial Diciembre. Págs. 795-811.

Sumario: 1. Introducción. 2. Metodología. 3. Contexto nacional e internacional de los inicios del periodismo lojano. 4. El primer periodismo lojano: 1856-1859. 5. Las hojas volantes, precursoras de la parti- 
cipación ciudadana en los medios. 6. La etapa del conservadurismo garciano: 1860-1875. 7. Pugnas ideológicas y prensa católica: 1875-1895. 8. Conclusiones. 9. Bibliografía.

\section{Introducción}

El periodismo de Loja, provincia del sur de Ecuador, desde sus inicios en 1856, hasta 1895 , merece la pena ser estudiado por su abundancia y valor periodístico, político y cultural. Cuantitativamente, llama la atención que en una provincia tan alejada geográficamente de los centros político y económico del país, y muy dependiente administrativamente, se haya producido un periodismo prolífico. Cualitativamente, además de ser un periodismo fuertemente ideológico, como en todo el siglo XIX, se destaca por el espíritu crítico y nivel intelectual de sus escritores, además de la importancia concedida al mundo de las letras y a la prensa católica.

Frente a ello, la historiografía del periodismo de Loja, pese al esfuerzo y dedicación de sus autores, adolece de imprecisiones y de ser estudios más descriptivos que analíticos. Nos referimos a Pío Jaramillo Alvarado (Literatura lojana, Quito, 1922), a Máximo Agustín Rodríguez (El periodismo lojano, Quito, 1948) y a Agustín Carrión (Breve historia del periodismo en Loja y sus escritores, Loja, 1918). A partir de estos trabajos surgieron otros sobre el periodismo lojano contemporáneo como 400 años de cultura lojana (Loja, 1975), de Hernán Gallardo Moscoso; Historia del periodismo lojano en sus cinco últimas décadas (Loja, 1990), de Arturo Armijos y El encanto del último rincón (Loja, 2005), de Oswaldo Burneo.

Probablemente, una de las limitaciones para realizar estudios de mayor alcance haya sido la falta de orden y conservación de las fuentes primarias de la historia del periodismo lojano. El abandono y dispersión de las mismas es aún hoy evidente, lo que obliga a acudir a hemerotecas de Quito y Guayaquil.

Todo ello hace especialmente necesaria la presente investigación en la que se buscan y recuperan las fuentes del periodismo lojano en su primera etapa (18561895) y se hace un análisis de las mismas desde el contexto político y sociocultural para caracterizarlas y apreciar el papel que desempeñaron. Un contexto muy convulso, normal en los primeros años de un joven país, nacido en1830, que hace que la primera prensa regional esté en estrecha dialéctica con los acontecimientos políticos. Así lo afirma Pío Jaramillo Alvarado cuando manifiesta que todo momento histórico importante de Loja está perpetuado por la publicación de algún periódico. Es el caso del periódico La Federación, de 1859, para algunos el primer periódico, que nace como instrumento de defensa del gobierno federal de Loja.

Por otro lado, el periodismo lojano, tardío respecto del inicio del periodismo ecuatoriano, fechado en 1792, suma a su abundancia el hecho de estar jalonado por brillantes figuras literarias que intervinieron en su fundación y desarrollo, lo que distingue al periodismo lojano del resto. 


\section{Metodología}

La metodología utilizada, por ser la fase inicial de investigación del periodismo lojano, ha consistido en la búsqueda de las fuentes primarias del mismo. Para ello, primero se definió el estado del arte de la investigación, mencionado en el apartado anterior, donde se destacan omisiones, imprecisiones y contradicciones. Esto evidencia la ausencia y falta de manejo de las fuentes primarias.

Con el apoyo de una matriz en línea, se fueron detectando dichos errores y verificando directamente en las hemerotecas toda la información secundaria hallada, fundamentalmente en la Biblioteca Aurelio Espinosa Pólit, en Quito, y en menor proporción en la Biblioteca de la Casa de la Cultura de Loja. Algunas fuentes, muy pocas, se encontraron en las bibliotecas de la Iglesia de Santo Domingo (Loja), del colegio Bernardo Valdivieso y de la Diócesis de Loja.

Por medio de fichas técnicas, con cada fuente se hizo una observación y registro de elementos cuantitativos (fecha, número de ediciones, dimensión, páginas, editores, precio, imagen de portada, etc...) y de elementos cualitativos (secciones, contenido, ideología, etc...) que fueron ingresados en una base de datos en línea. El alcance de este estudio no implicaba todavía un análisis profundo de contenido, que es un objetivo posterior, pero sí un primer esfuerzo interpretativo de la relación de los periódicos y revistas de cada etapa con su entorno histórico y sociocultural. Subrayemos el enfoque histórico que anima esta investigación que no es la catalogación y acumulación fría de datos sino estudiar la comunicación como factor de cohesión social al que ninguna dimensión de lo humano le es ajeno.

\section{Contexto nacional e internacional de los inicios del periodismo lojano}

La imprenta llega a la ciudad de Ambato, en la Real Audiencia de Quito, actual Ecuador, en 1755, dos siglos después de la primera imprenta en América que fue la de México, en 1532, seguida por Lima, que la tuvo en 1584 (Stols, 1953: 7). Esta diferencia temporal para Stols es explicable porque Lima quiso proteger su industria tipográfica y controlar mejor lo que se imprimía, además de que las órdenes religiosas que se iban afincando en la Real Audiencia ya tenían en Europa sus encargos de impresiones y sus inversiones hechas.

Al igual que en México, fueron las necesidades evangelizadoras, en este caso de los jesuitas de Quito, las que propiciaron la importación de la primera imprenta, del mismo modo que fueron los jesuitas los que llevaron la imprenta en la mayoría de países de Sudamérica: en la misión boliviana de Julí (1610), en Loreto, Paraguay (1703), en Córdova de Tucumán, Argentina (1766), etc... Además, si comparamos a Ecuador con otros países del continente, su imprenta no fue tan tardía, pues Colombia la tuvo apenas 16 años antes (1739), mientras que otros países contaron con ella 
bastante tiempo después: Venezuela en 1806, Chile en 1812, Paraguay en 1807 y Brasil, Río de Janeiro, en 1808.

En Ecuador, el primer periódico propiamente es Primicias de la cultura de Quito, fundado el 5 de enero de 1792 en Quito, por Eugenio de Santa Cruz y Espejo, y de contenido netamente literario. Salvando este caso, se puede decir que el primer periodismo ecuatoriano surge en el ambiente revolucionario iniciado con la gesta del 10 de agosto de 1809 en Quito, el llamado primer grito de independencia. En Guayaquil estalla la revolución independentista el 9 de octubre de 1820 y el primer periódico, El Patriota de Guayaquil, aparece en mayo de 1821, un mes después de llegada la imprenta. En Cuenca, pese a que el golpe revolucionario fue un mes después que el de Guayaquil, El Eco del Azuay no sale a la luz hasta enero de 1828.

\section{Primer periodismo lojano: 1856-1859}

Así como el primer periodismo ecuatoriano, exceptuando Primicias, surge a partir del ambiente revolucionario de Quito, el periodismo lojano nace alrededor de otra convulsión como fue la división del país en 1859 y la proclamación de Loja como provincia federal. El inicio tardío de la prensa lojana también se debe a que la imprenta no llega hasta 1855, seguida después de la imprenta del Gobierno (1864) y la del Clero (1866) (Rodríguez, 1948:1-2). Subrayemos que en la última década del XIX Loja llegó a tener cuatro imprentas más: la de Manuel Zárate, la del Colegio Bernardo Valdivieso y la Tipografía Republicana, propiedad de la Sociedad Republicana. Le siguió a Cuenca en número, lo cual explica su fructífera producción periodística e impresora en general (Rodríguez, 2008:56).

Pero hay un motivo más de esta fecundidad periodística y es el desarrollo cultural que caracterizó a Loja desde la colonia. En 1727 fue de las pocas poblaciones, aparte de Quito, que contó con colegio y posteriormente también escuela, ambos dirigidos por los jesuitas (Jaramillo, 2002: 239). Por las "cátedras de latinidad y humanidades" que se impartían en el colegio de Loja pasaron muchas generaciones que se destacaron por su cultura en la universidad de Quito o que siguieron autoeducándose en Loja. Fue por ello que Loja tuvo destacados representantes legislativos en los distintos períodos parlamentarios, tanto durante la Gran Colombia (1822-1830) como en la República (Jaramillo, 1922: 7).

El contexto político del primer periodismo lojano es el de una joven república, apenas fundada en 1830, jalonada de gobiernos militares, sobre todo el de José María Urvina, de tinte liberal y nacionalista criollo, y en riesgo siempre de invasiones peruanas. Todo ello desemboca en la crisis de 1859 en que se proclaman tres gobiernos simultáneos: en Quito, Guayaquil y Loja, y en este último caso se tratará de un gobierno federal (Salvador Lara, 2010:140 y ss.). En estos momentos se funda $L a$ Federación (1859), que para muchos supone el despegue del periodismo lojano. 
Para Pío Jaramillo (2002:366), la crisis del 1859, y el papel de Loja en la misma, es entendible por la situación de abandono que padecieron las provincias en esos primeros 30 años de la República, caracterizados, a excepción de algunos gobiernos civilistas, por el militarismo extranjero de Flores o nacionalistas criollos, en los que predominó la intriga política, la traición a las instituciones democráticas y el derroche del erario público.

Pero hay un elemento adicional en la proclamación del gobierno federal de Loja: un sentimiento histórico forjado amargamente en los duros años de la independencia, que describe Pío Jaramillo: "Loja, por su posición fronteriza, fue víctima del vandalaje de las tropas colombianas y peruanas, de la rapacidad de los jefes militares y de la opresión y vejamen de las autoridades departamentales que funcionaban en Cuenca" (íbid, 348). Por ello, en ese momento, Loja no solo proclamaba un gobierno federal autónomo, no separatista, sino que reivindicaba una deuda histórica que tenía el país con ella.

En los años previos de este agitado ambiente político surge el primer periodismo, que para Oswaldo Burneo inicia con El lojano, el 6 de junio de 1856 (Burneo, 2005:278), publicación que también menciona un editorial del diario lojano $E l$ Mundo en su primer número el 10 de agosto de 1976 (Armijos, 1990:92), pero que no hemos hallado. Lo mismo ocurre con El Zamora, periódico que supuestamente apareció el 6 de agosto de 1858. El periódico más antiguo localizado es Las márjenes del Zamora, fundado el 24 de octubre de 1856, aunque la edición que hemos obtenido es su segundo número (20-11-1856). Parece un periódico oficial pues en la portada se publican una serie de cartas del gobernador de la provincia de Loja a los autores de un informe sobre la situación de la provincia, pidiéndoles que interrumpan dicha impresión y la difusión del informe. Este periódico no lo recoge ni Agustín Carrión ni Máximo A. Rodríguez.

El segundo periódico localizado, para muchos el primero, es La federación, aparecido el 8 de octubre de 1859 (Rodríguez, 2008:43), con el subtítulo de periódico oficial pues, efectivamente, nace como órgano del movimiento federalista. De hecho la portada del número 3 (28-10-1859), que es la única que se ha podido conseguir (Gráfico 1), se dedica exclusivamente al decreto del Jefe militar y político del nuevo gobierno. Jaramillo lo data en 1856, Carrión en el 2 de octubre de 1859 y Rolando, en 1860, lo que evidencia la imprecisiones históricas por la falta de manejo de las fuentes.

La federación no nació solo para ser el órgano de difusión del federalismo. Ciertamente que su fundador, el colombiano Benjamín Pereira Gamba, influyó con las ideas federalistas traídas de su país, pero su preocupación también fue de índole literaria. Según narra Pío Jaramillo (1922: 10), por La Federación pasaron las plumas lojanas más connotadas del momento, que hasta entonces habían publicado en los periódicos de Quito y Guayaquil, así como la de aquellos que se iniciaban en el mundo literario.

Subrayemos nuevamente el rico ambiente cultural de la ciudad, propiciado ahora por el colegio La Unión, fundado en 1857 por el mismo Pereira Gamba y por otros 
dos compatriotas: Belisario Peña y Francisco Ortiz Barrera. Los tres eran notables profesores y literatos que llegaron a la ciudad por pedido expreso de Miguel Riofrío, afamado intelectual lojano y diplomático en Colombia (Jaramillo, 2002: 390). El colegio hizo una importante labor cultural, pues sus alumnos destacaron literariamente dentro y fuera de Loja, y alcanzó tan buena fama por sus métodos pedagógicos que a los dos años sus mentores fundaron otro con el mismo nombre en Quito. En diciembre de 1859, el gobierno federal de Manuel Carrión Pinzano fusionó el colegio con el San Bernardo (antiguo colegio de los jesuitas), constituyendo un Instituto de Instrucción Secundaria con las cátedras de Jurisprudencia, Medicina y Teología (íbid: 372).

La Federación, claramente liberal, tuvo dieciséis ediciones y duró lo que el gobierno federal, cerca de un año y medio, pues su último número data del 5 de enero de 1861 (Rodríguez, 2008: 44).

Gráfico 1: Portada del número 3 de La Federación (28-10-1859).

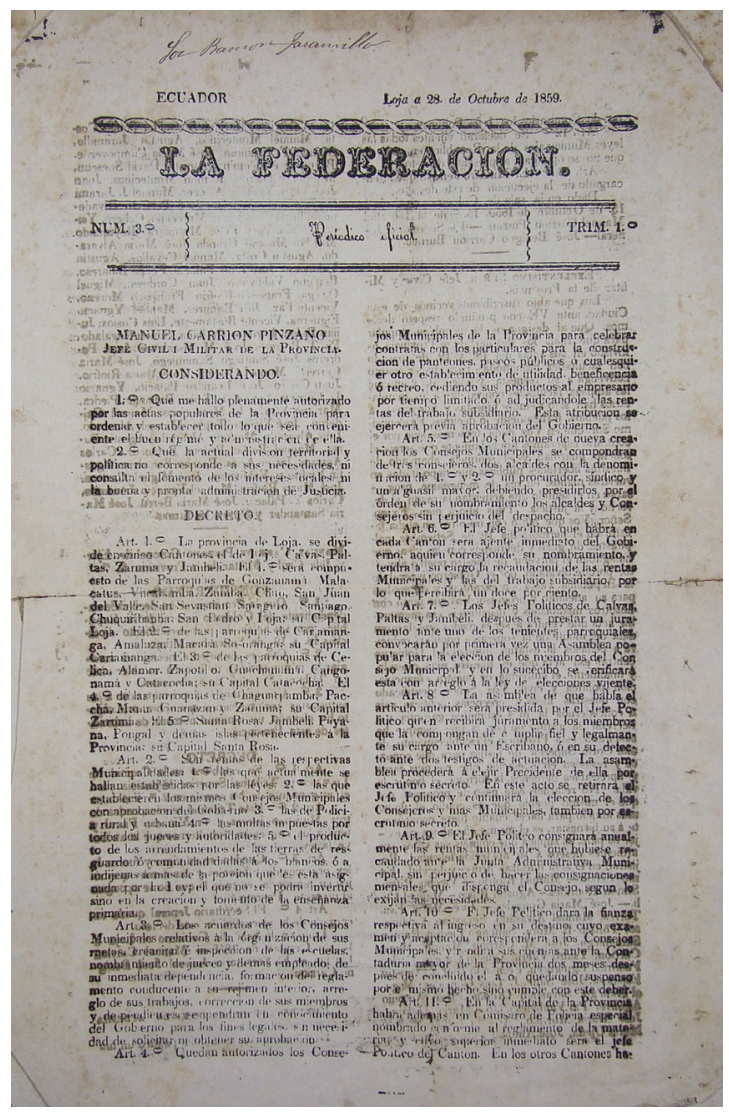

Fuente: Biblioteca Aurelio Espinosa Pólit. 


\section{Las hojas volantes, precursoras de la participación ciudadana en los medios}

A los periódicos publicados hay que añadir un fenómeno periodístico apenas registrado por la historiografía. Nos referimos a las hojas volantes u hojas sueltas, género que proliferó durante todo el siglo XIX nada más llegar la imprenta a Ecuador. Para algunos historiadores, como Antonio Checa, son una especie de protoperiodismo. En el caso de Loja fueron utilizadas para la comunicación propagandística de las autoridades locales, para informar de hechos religiosos o para expresar la opinión de grupos de ciudadanos o de personas particulares. En este último sentido las podríamos considerar como un excelente vehículo de la opinión pública y precursores de la participación de los lectores en la prensa.

Según el Calendario Histórico del Ecuador de Benjamín Pereira Gamba (1863: 9) fue el 29 de mayo de 1856, de la cual no tenemos evidencia. Las siguientes, localizadas en la Biblioteca Aurelio Espinosa Pólit (Quito), son Hermandad de Beneficencia Funeraria, de 1857; Al público (24-11-1858), que es una arenga del Gobernador de Loja ante la amenaza de invasión peruana; Manifestación (30-11-1858), que es una comunicación dirigida al Presidente de la República (Gral. Robles) y Parte oficial (1864).

Se editarán hojas con anuncios de actos literarios como Certámenes del Colegio Nacional San Bernardo de Loja $(1867,1877)$ y Programa de los actos literarios del colegio seminario San Francisco Javier (1871), lo cual evidencia el ambiente cultural lojano. También hay otras hojas volantes religiosas, entre ellas, Revista Pastoral (1867) y el Segundo sínodo diocesano (1872) acontecimiento que se dio en Loja. Asimismo se publican hojas como Al Público (1873) en la que se invita a los jóvenes a estudiar con ciertos reglamentos católicos, y Pía Unión en honra de la Virgen María (1873).

Y hojas volantes de carácter civil como Voces que alarman (1874), Al Ministro Sr. Doctor Ramón Samaniego, publicación de tres hojas el 26-5-1874.

Todas estas publicaciones, halladas en la Biblioteca Ecuatoriana Aurelio Espinosa Pólit, no han sido recogidas ni por el guayaquileño Ceriola ni por los historiados lojanos Agustín Carrión, Máximo A. Rodríguez y Pío Jaramillo, y ha pasado desapercibida su importancia.

\section{La etapa del conservadurismo garciano: 1860-1875}

Abre esta etapa la reunificación que hace del país Gabriel García Moreno, que vence en septiembre de 1860 al general guayaquileño Guillermo Franco, que estaba apoyado por Perú, y convoca la Asamblea Nacional y las elecciones para el 8 de enero de 1861, la cual aprobará la séptima constitución del país y le elegirá a él como 
presidente para el período 1861-1865, aunque retomó el poder en 1869 hasta 1875 (Salvador Lara, 2012: 150-151).

Indiscutiblemente, García Moreno es el político ecuatoriano más destacado y controvertido del siglo XIX. Es el máximo exponente del conservadurismo, que ejerció con mano dura, y en nombre de un catolicismo que interpretó de modo extremista y rigorista, cuestionado por creyentes y no creyentes. Odiado y aclamado a la vez, lo cierto es que desarrolla una labor civilizadora y progresista de gran magnitud pues inició el sufragio universal popular y directo, fomentó la enseñanza y la investigación científica, desarrolló la vialidad, reorganizó la hacienda pública y firmó el Concordato con la Santa Sede en 1862. La prensa no gozó de amplia libertad y se clausuraron periódicos opositores pero eso no impidió que existieran periódicos combativos contra el régimen, como Centinela en Cuenca y La Nueva Era en Guayaquil, en 1873 (Ceriola, 1909: 82).

En relación con Loja, García Moreno respetó el gobierno federal de Manuel Carrión Pinzano y visitó la ciudad para firmar un convenio de mutua aceptación el 23 de marzo de 1860. Debido a ello, en octubre de ese año Carrión se adhirió a la convocatoria de Asamblea Nacional y elecciones y el mismo día de su celebración (8-1-1861) renunció a su cargo finalizando con ello el federalismo (Jaramillo, 2002: 383 y ss.). En este breve periodo, como ya dijimos, será La federación el órgano de defensa del federalismo. Así lo refleja el editorial "Derecho de Loja para federarse" de la edición del 17-3-1860.

A finales de 1861, según Rodríguez, nace La Cabaña de Surirán, que a partir de su séptimo número (15-5-1862) pasará a ser La Cabaña. Era de periodicidad ocasional y contenía temas políticos, religiosos así como artículos literarios. Tanto Carrión como Carlos A. Rolando lo datan en 1863.

En un ambiente de escasa libertad de prensa, es comprensible la aparición de periódicos oficiales o afines al gobierno, como es La Concordia (1862) y La Defensa Nacional (1864). El primero, mensual y oficial (bajo su cabecera anuncia que las suscripciones se hacen en la Gobernación), aunque se autodenomine periódico semioficial. El número más antiguo hallado es el $6^{\circ}$, del 1-12-1862, en el que consta el editorial "Los criticones", donde se reflexiona sobre la vulnerabilidad de los mandatarios ante la crítica siempre severa de la opinión pública. El segundo, quincenal, que en su primer número (1-1-1864), en el prospecto o presentación declara su vocación de defensa del gobierno y del país ante el conflicto fronterizo con Colombia. Rodríguez data al primero en 1863 y al segundo lo omite.

También surgen periódicos críticos como El Constitucional (1865), de ideología liberal, como se manifiesta en el prospecto de su primera edición (1-1-1865) (Gráfico 2). Fue clausurado por García Moreno pues defendió en las elecciones presidenciales de ese año al candidato de oposición.

Según Agustín Carrión (1918: s/n), en 1868 aparece El Labrador, aunque no lo hemos hallado en ninguna hemeroteca; era un periódico eventual, literario, satírico 
y reformador de las costumbres lugareñas. Según Jaramillo (1922: 13), tanto en este periódico como en Brisas del Zamora, ambas efímeras, publicaron sus creaciones los literatos lojanos.

Aparecerán además publicaciones literarias como Brisas del Zamora (1867) y el periódico cultural quincenal El estudiante, que en el prospecto de su primer número, del 15-7-1873, además de hacer un alegato en tono irónico de la condición de estudiante anuncia que publicará gratis todo escrito literario. Además, se imprimen toda una serie de hojas volantes de tipo cultural ya mencionadas.

Gráfico 2: Portada del número 1 de El Constitucional (1-1-1865).

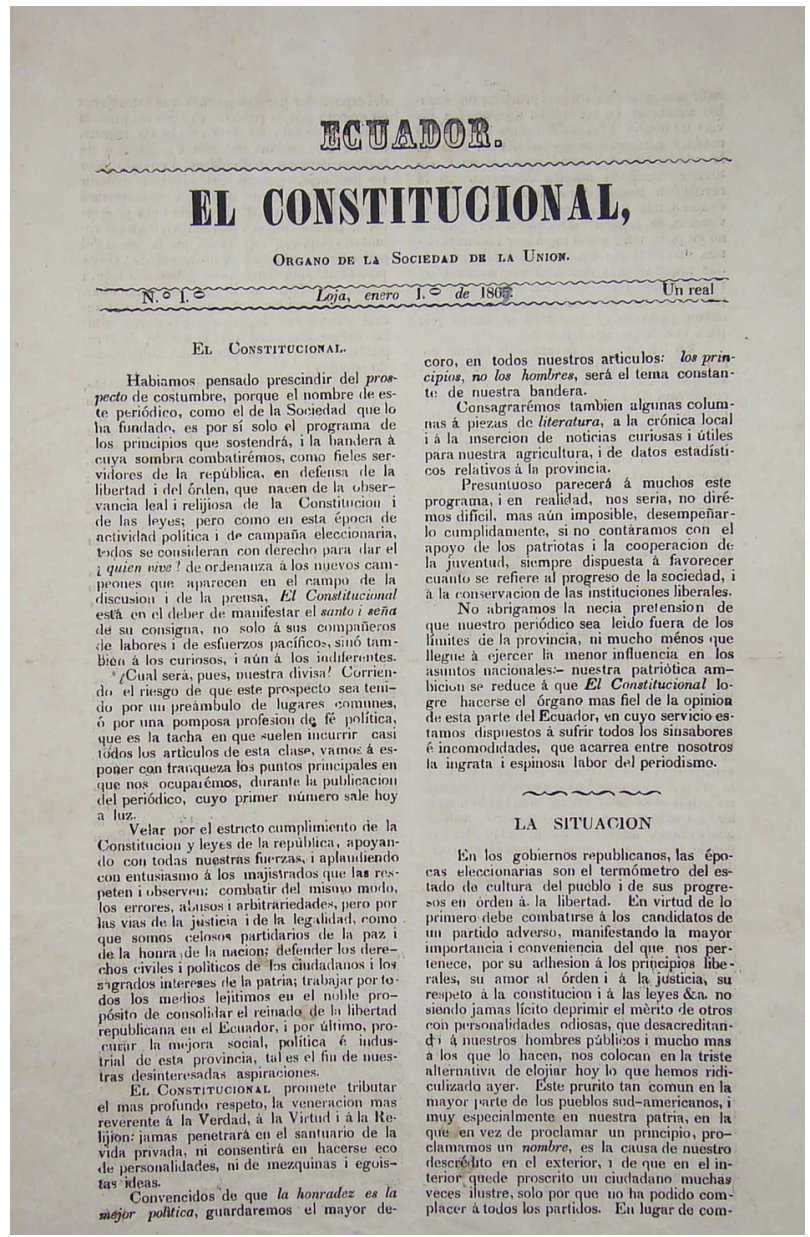

Fuente: Biblioteca Aurelio Espinosa Pólit. 


\section{Pugnas ideológicas y prensa católica: 1875-1895}

A partir del 6 de agosto de 1875, cuando fue asesinado García Moreno, se inician veinte años de una etapa llamada progresista porque domina el poder dicho partido, a modo de liberalismo católico o conservadurismo progresista, tránsito del conservadurismo garciano al liberalismo alfarista. Convivirá con otros tres partidos: el Conservador garciano -prácticamente aniquilado con el asesinato de García-, el Liberal y el Liberal Radical, de Alfaro. Todos los gobiernos son constitucionales menos el del general Ignacio de Veintemilla que gobernó dictatorialmente entre 1876 y 1883, año convulso, de múltiples guerrillas opositoras, que fueron unificadas por el general Salazar, logrando vencer y expulsar al dictador en julio de ese año (Salvador Lara, 2012: 165 y ss.). Pese a ello, se suceden continuos estallidos revolucionarios de los radicales alfaristas, las llamadas montoneras, que fueron especialmente duras desde 1885, y que en 1886 asaltaron Loja, aunque fue reconquistada cinco días después.

Estos hechos fueron objeto de numerosas hojas volantes tanto en 1875 (Alarma, Los ayeres del pueblo, etc...) como en 1876 (Escándalo sobre escándalo, Pío IX y los enemigos de la Iglesia, etc...).

El 4 de septiembre de 1875 se publica el periódico semanal conservador El ciudadano, que en el prospecto de su portada, hallada en la Biblioteca Carlos A. Rolando, hace toda una apología de García Moreno y apoya al progresista Borrero. Rolando lo data en 1876. Por su parte, los liberales moderados lojanos publican su periódico quincenal El cinco de enero, el 9 de junio de 1877, periódico de la Gobernación, según Carrión; su ideología la critica en su primer número el también liberal La voz del Zamora, nacido el 23 de ese mismo mes, que tuvo el rechazo del obispo Masiá. El quincenario católico El deber (1879) nace en oposición a La Sociedad, liberal nacido el 5-10-1879 que en su primer número proclama su oposición al obispo. Curioso es el periódico El intérprete (8-11-1879) que aparece en oposición a El deber pero en tono jocoso. Otro periódico católico será El amigo del pueblo (1879), liberal moderado.

Hojas como La voz del pueblo (21-9-1878), de la imprenta del Gobierno, verdadera defensa del gobernador de la provincia, son reflejo de la propaganda oficial. Esa imprenta publicó el año anterior numerosas hojas: La cuestión político religiosa, Una verdad, Benigno Carrión y El Lojano imparcial, entre otras. La imprenta del seminario hará lo propio con hojas como A los lectores de Loja (1877). Otros impresores que publicarán varias hojas de tinte político especialmente serán Ramón Alcocer, J. Antonio Herdoíza, J. Ojeda y Manuel de J. Alvarado. Varias de estas hojas surgieron con motivo de la campaña de Restauración de Salazar y otras eran de tipo religioso. Importante también en producción de hojas fue la Imprenta republicana y la del colegio Bernardo.

Periódicos abiertamente opositores al dictador Veintemilla y vehículo de la campaña llamada de la Restauración, dirigida por el general Salazar, serán el eventual El diez y siete de noviembre (1881) y el quincenal La voz del sur, que Rodríguez 
data en el 25-11-1882 pero en la Biblioteca Aurelio Espinosa Pólit se encuentra el primer número, del 18-11-1882, dos días después de la gesta realizada por Salazar al entrar en Loja y expulsar a las fuerzas oficiales. En la portada (Gráfico 3), después de anunciarse como órgano de la restauración, aparece toda una síntesis de su razón de ser: "Guerra a la Dictadura. Guerra a los partidos de Hombres. Luchar porque imperen los principios. En una palabra: por la ¡iREPÚBLICA!! Tal es la única y suprema aspiración de los R.R. de este periódico.” Según Rodríguez fue un periódico de larga duración pues hay constancia de la edición número 23.

En medio de toda esta agitación, surge el Liceo del colegio Bernardo Valdivieso (antes San Bernardo y colegio de Loja de los jesuitas), que contaba con su propia imprenta, y que para Pío Jaramillo (1922:14) fue el primer cenáculo de desarrollo cultural y el más duradero. Publicará el periódico literario mensual La flor del Zamora (1885), de orientación católica y publicaciones literarias manuscritas como El principiante y La Flor andina, ambos de 1889. También el colegio había impreso por unos meses en 1879 La Crónica, con información general de la vida política y social.

El Seminario Menor, con su Órgano de la Academia Científico Literaria, contribuirá también al ambiente cultural del momento con la publicación en 1887 de la revista mensual La abeja.

Un periódico conservador progresista fue El patriota (24-4-1886), que en su primer número refleja la idiosincrasia y sentir lojanos en el editorial "Porvenir de Loja", en el que hace un recuento de la explotación y saqueo sufridos por la provincia. Carrión data su primer número en octubre de ese año. Lo mismo vemos en el periódico $E l$ fénix (1886).

El periódico más duradero y serio de Loja, según Rodríguez, será El lábaro (1887), cuyo principal redactor fue Daniel de J. Ojeda, deán de la catedral y escritor destacado. Según Jaramillo, este periódico católico también sobresalió por los poetas que escribieron. Igualmente católico será El Microscopio (1890), que según Carrión será un periódico satírico, contrario al liberalismo y con ingeniosas caricaturas, editado por Juventino Vélez, editor de El Lábaro. Será también Vélez el redactor de La escoba, cuyo estilo satírico es apreciable en la frase que aparece bajo la cabecera de su segundo número (16-4-1889): "Esta hojilla se publicará cada vez que sea necesario y haya basura que barrer. Se repartirá gratis." Tanto La Escoba como El Microscopio se reeditaron en Quito (Carrión, 1918: s/n).

El 28 de marzo de 1891 aparece El correo del sur, editado por Serafín A. Larriva, que se declara en su prospecto defensor del partido republicano. Curiosamente, defiende el mismo lema que El Patriota: "El poder en la ley, la justicia en el derecho, la libertad en el orden, la moral en todo", salvo que en éste consta también "la soberanía en el pueblo". El mismo Larriva, destacado abogado y escritor, y en la misma imprenta republicana, junto con Ángel R. Ojeda fundará El Eco del sur (1893), dedicado a la "Jurisprudencia, Política, Literatura e Intereses generales", como reza bajo 
su cabecera, y llama la atención por constar por primera vez anuncios publicitarios en la portada.

Publicaciones literarias serán el quincenal El Porvenir (1892), del colegio Bernardo Valdivieso y su continuación El Nuevo Horizonte (1895), así como Hojitas blanquinegras (1892), de tipo religioso y redactada por las señoras y señoritas de la Tercera Orden Dominicana (Rodríguez, 2008:55).

Un capítulo especial merecería el periodismo lojano fuera de Loja. Fueron varios los literatos y periodistas de gran valía que se asentaron en Quito y Guayaquil y realizaron una intensa labor periodística: Vicente Paz, Manuel y Segundo Cueva, Belisario Moreno y Rafael Riofrío, Especialmente Paz fundó en Guayaquil varios: La Nación, El Grito del Pueblo Ecuatoriano, El Correo del Guayas y El Ecuatoriano (1922:14-15).

Gráfico 3: Portada del número 1 de La Voz del Sur (18-11-1882)

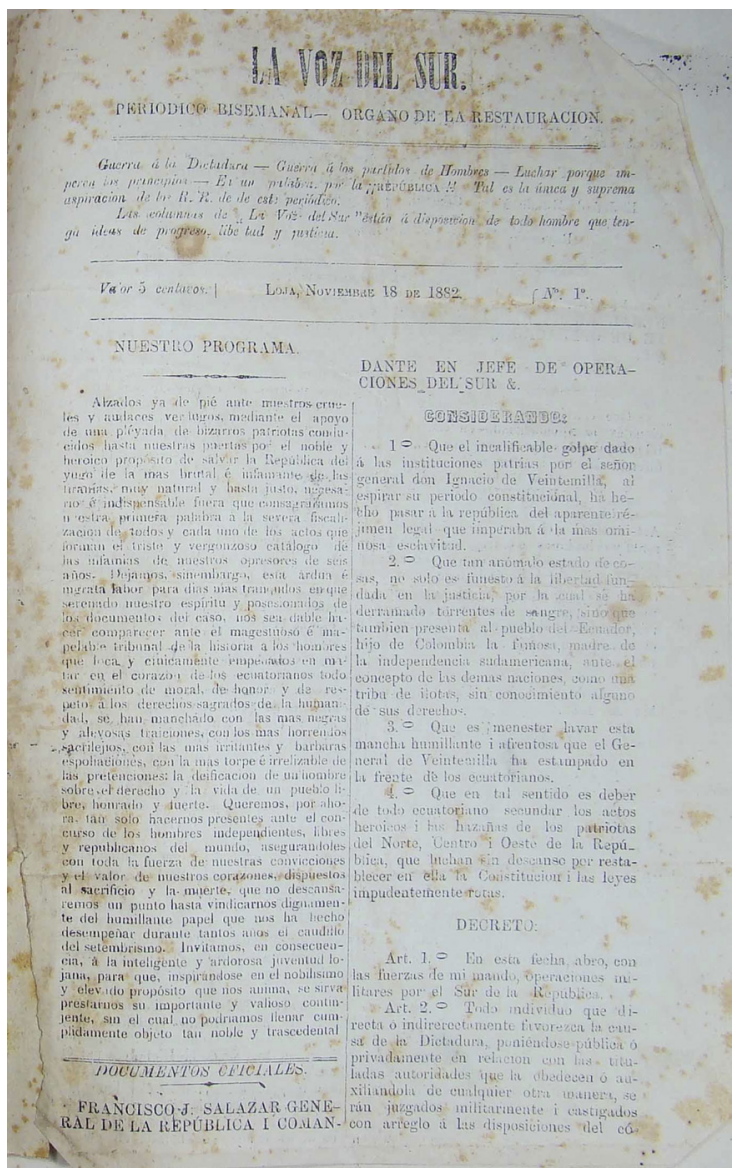

Fuente: Biblioteca Aurelio Espinosa Pólit. 


\section{Conclusiones: fuentes y rasgos característicos del primer periodismo lojano}

En primer lugar, del recorrido por el primer periodismo lojano desde 1856 hasta 1895 es destacable su abundancia pues se publicaron 27 periódicos y ocho revistas, frente a once periódicos en Ambato, ocho en Latacunga, siete en Riobamba, y tres en Ibarra, por mencionar poblaciones similares. A ello se añaden 91 hojas volantes, que apenas son mencionadas en la historiografía pero que constituyen un periodismo incipiente y un objeto de estudio muy interesante por la participación ciudadana que implican y el reflejo que hacen de la sociedad.

En segundo lugar, el estudio saca a flote el descuido y la dispersión en que se encuentran los fondos hemerográficos de la prensa lojana. Ninguna biblioteca pública ni privada de la ciudad contiene la colección completa de los periódicos y revistas publicados, y mucho menos digitalizados, lo que evidencia la falta de visión y de políticas de conservación de este valioso patrimonio cultural, con el riesgo de su extinción. Esta carencia ha podido ser cubierta gracias a la valiosa hemeroteca digital de la Biblioteca Ecuatoriana Aurelio Espinosa Pólit en Quito, dirigida por la Compañía de Jesús, o a la Biblioteca Rolando del Municipio de Guayaquil, cuyos valiosos fondos están en lamentable estado.

En cuanto al contenido de los periódicos, como ocurre en todo el periodismo del siglo XIX, la prensa es esencialmente un vehículo ideológico. Concretamente en Loja, los periódicos nacen, en su mayoría, para defender al gobierno de turno o a un partido político determinado. Ciertamente, predominan los periódicos conservadores y progresistas, la mayoría afines o respetuosos de los principios cristianos, así como los periódicos abiertamente católicos, lo cual refleja la sociedad lojana del momento. Pero quizás lo más llamativo es que en medio de los agitados momentos los periódicos fueron también importantes soportes del quehacer literario e intelectual de sus escritores. La impresión de siete revistas o publicaciones culturales lo corroboran.

Mención especial merece la prolífica actividad de las imprentas en la producción de 91 hojas volantes, 88 de las cuales hallamos físicamente. Muchas eran hojas propagandísticas del gobernador de turno y otras de las distintas facciones políticas pronunciándose sobre los acontecimientos y arengando en uno u otro sentido. Otras, simplemente de ciudadanos expresando su opinión o defendiendo su honor. Estas hojas dan fe de una sociedad, además de culta, crítica y reivindicativa y, como modo de expresión ciudadana, las podríamos considerar un anticipo de la participación de las audiencias que hoy fomenta el ciberperiodismo.

En definitiva, estudiar el periodismo de Loja es descubrir una sociedad bastante adelantada culturalmente y activa políticamente, y que desde el principio vio en la prensa un gran aliado cultural y un espacio de debate político. Es por eso que a través de la historia de la prensa lojana descubrimos una sociedad, unos valores culturales y religiosos y un pensamiento que sobresalió en su época. Ante ello hay que lamentar el escaso cuidado de este patrimonio cultural y, acaso debido a esto, el insuficiente 
estudio sobre ello. Con este trabajo, primero de una serie, se busca recuperarlo y reconocer debidamente su contribución en la construcción de la sociedad lojana.

\section{Bibliografía}

ARMIJOS AYALA, Arturo (1990). Historia del periodismo lojano en sus cinco últimas décadas. Loja: Casa de la Cultura Ecuatoriana.

BURNEO CASTILLO, Oswaldo (2005). El encanto del último rincón. Loja: Editorial Universidad Técnica Particular de Loja.

CARRIÓN, Agustín (1918). Breve historia del periodismo en Loja y sus escritores. Loja: El Heraldo.

CERIOLA, Juan Bautista (1909). Compendio de la historia del periodismo en el Ecuador. Quito: Biblioteca Casa de la Cultura Ecuatoriana.

CHECA GODOY, A. (1993). "El periodismo ecuatoriano en el XIX", "El Ecuador liberal, 1895-1934", "La prensa ecuatoriana en la era de Velasco Ibarra", en Historia de la prensa en Iberoamérica. Sevilla: Alfar.

JARAMILLO ALVARADO, Pío (2002). Historia de Loja y su provincia. Guayaquil: Senefelder. ( $4^{\mathrm{a}}$. edición). Guayaquil.

(1922). Literatura lojana. Quito: Imprenta de la Universidad Central del Ecuador.

PEREIRA GAMBA, Benjamín (1863). Calendario histórico del Ecuador. Loja: Casimiro Cano.

RODRÍGUEZ, Máximo Agustín (1948). El periodismo lojano. Quito: Publicaciones de la Casa de la Cultura Ecuatoriana.

(2008): El periodismo lojano y Escritos de prensa. Loja: Ilustre Municipio de Loja ( $2^{\mathrm{a}}$. ed. aumentada).

ROLANDO, Carlos A. (1920). Cronología del periodismo ecuatoriano: seudónimos de la prensa nacional. Guayaquil: Imprenta y papelería mercantil-Monteverde \& Velarde.

SALVADOR LARA, Jorge (2010). Breve historia contemporánea del Ecuador. Bogotá: Fondo de Cultura Económica.

STOLS, Alexander A.M. (1953). Historia de la imprenta en el Ecuador de 1755 a 1830. Quito: Casa de la Cultura Ecuatoriana. 


\section{Anexos}

10.1. Relación de periódicos publicados en Loja en el período 1856-1895.

\begin{tabular}{|c|c|c|}
\hline Publicación & Año/fecha aparición & Ubicación física/fuente \\
\hline El lojano & $6 / 6 / 1856$ & $\begin{array}{l}\text { Fuente: El encanto del último rincón (Oswal- } \\
\text { do Burneo, 2005). }\end{array}$ \\
\hline Las Márjenes del Zamora & $24 / 10 / 1856$ & $\begin{array}{l}\text { Localización: Bibllioteca Ecuatoriana Aurelio } \\
\text { Espinosa Pólit (BEAEP). Número encontra- } \\
\text { do: } 2,20 \text { de noviembre de } 1856 .\end{array}$ \\
\hline El Zamora & $6 / 8 / 1858$ & $\begin{array}{l}\text { Fuente: El encanto del último rincón (Oswal- } \\
\text { do Burneo, 2005). }\end{array}$ \\
\hline La Federación & $8 / 10 / 1859$ & $\begin{array}{l}\text { Localización: BEAEP. Número encontrado: } \\
3,28 \text { de octubre de } 1859\end{array}$ \\
\hline La Cabaña & 1861 & $\begin{array}{l}\text { Fuente: El periodismo lojano (Máximo Agus- } \\
\text { tín Rodríguez, 1948) }\end{array}$ \\
\hline La Concordia & 1862 & $\begin{array}{l}\text { Localización: BEAEP. Número encontrado: } 6 \text {, } \\
1 \text { de diciembre de } 1862 \text {, mensual. }\end{array}$ \\
\hline La Defensa Nacional & $1 / 1 / 1864$ & $\begin{array}{l}\text { Localización: BEAEP. Número encontrado: } 1 \text {, } \\
1 \text { enero de } 1864 \text {, quincenal. }\end{array}$ \\
\hline El Constitucional & $1 / 1 / 1865$ & $\begin{array}{l}\text { Localización: BEAEP. Número encontrado: } 1 \text {, } \\
1 \text { de enero de } 1865 \text {, quincenal. }\end{array}$ \\
\hline El labrador & 1868 & $\begin{array}{l}\text { Fuente: Breve historia del periodismo en Loja } \\
\text { y sus escritores (Agustín Carrión, 1918) }\end{array}$ \\
\hline El estudiante & $15 / 07 / 1873$ & $\begin{array}{l}\text { Localización: BEAEP. Número encontrado: } 1 \text {, } \\
15 \text { de julio de } 1873 \text {, quincenal. }\end{array}$ \\
\hline El ciudadano & $4 / 9 / 1875$ & $\begin{array}{l}\text { Localización: BEAEP. Número encontrado: } 1 \text {, } \\
4 \text { de setiembre de } 1875 \text {, semanal. }\end{array}$ \\
\hline El cinco de enero & $9 / 6 / 1877$ & $\begin{array}{l}\text { Localización: BEAEP. Número encontrado: } 1 \text {, } \\
9 \text { de junio de } 1877 \text {, quincenal. }\end{array}$ \\
\hline La voz del Zamora & $23 / 6 / 1877$ & $\begin{array}{l}\text { Localización: BEAEP. Número encontrado: } 1 \text {, } \\
23 \text { de junio de } 1877 \text {, quincenal. }\end{array}$ \\
\hline La voz del pueblo & $21 / 09 / 1878$ & $\begin{array}{l}\text { Localización: BEAEP. Número encontrado: } 1 \text {, } \\
21 \text { de septiembre de } 1878 \text {. }\end{array}$ \\
\hline La sociedad & $5 / 10 / 1879$ & $\begin{array}{l}\text { Localización: BEAEP. Número encontrado: } 1 \text {, } \\
5 \text { de octubre de } 1879 \text {. }\end{array}$ \\
\hline El deber & 1879 & $\begin{array}{l}\text { Fuente: Breve Historia del periodismo en } \\
\text { Loja y sus escritores (Agustín Carrión, 1918) }\end{array}$ \\
\hline El amigo del pueblo & 1879 & $\begin{array}{l}\text { Fuente: Breve Historia del periodismo en } \\
\text { Loja y sus escritores (Agustín Carrión, 1918) }\end{array}$ \\
\hline El intérprete & $8 / 11 / 1879$ & $\begin{array}{l}\text { Localización: BEAEP. Número encontrado: } 1 \text {, } \\
8 \text { de noviembre de } 1879 \text {. }\end{array}$ \\
\hline La crónica & $8 / 7 / 1879$ & $\begin{array}{l}\text { Fuente: Breve Historia del periodismo en } \\
\text { Loja y sus escritores (Agustín Carrión, 1918) }\end{array}$ \\
\hline El diez y siete de noviembre & 1881 & $\begin{array}{l}\text { Localización: BEAEP. Número encontrado: } 3 \text {, } \\
1 \text { de diciembre de } 1883 \text {, mensual. }\end{array}$ \\
\hline
\end{tabular}




\begin{tabular}{|l|l|l|}
\hline La voz del sur & $18 / 11 / 1882$ & $\begin{array}{l}\text { Localización: BEAEP. Número encontrado: 1, } \\
18 \text { de noviembre de 1882, bisemanal. }\end{array}$ \\
\hline El patriota & $28 / 4 / 1886$ & $\begin{array}{l}\text { Localización: Biblioteca Carlos A. Rolando } \\
\text { (Biblioteca Munic. Guayaquil). Número } \\
\text { encontrado: 1, 28-04-1886. }\end{array}$ \\
\hline El fénix & 1886 & $\begin{array}{l}\text { Fuente: Breve Historia del periodismo en } \\
\text { Loja y sus escritores (Agustín Carrión, 1918), } \\
\text { quincenal. }\end{array}$ \\
\hline El microscopio & 1890 & $\begin{array}{l}\text { Localización: Biblioteca Carlos A. Rolando } \\
\text { (Biblioteca Munic. Guayaquil). }\end{array}$ \\
\hline El correo del sur & $28 / 3 / 1891$ & $\begin{array}{l}\text { Localización: BEAEP. Número encontrado: 1, } \\
\text { 28 de marzo de 1891, semanal. }\end{array}$ \\
\hline El eco del sur & 1893 & $\begin{array}{l}\text { Localización: BEAEP. Número encontrado: } \\
\text { s/f, quincenal. }\end{array}$ \\
\hline El rayo & 1895 & $\begin{array}{l}\text { Fuente: Breve historia del periodismo en Loja } \\
\text { y sus escritores (Agustín Carrión, 1918) }\end{array}$ \\
\hline
\end{tabular}

10.2. Relación de revistas publicadas en Loja en el período 1856-1895.

\begin{tabular}{|l|l|l|}
\hline Publicación & Año/fecha aparición & Ubicación física/fuente \\
\hline Brisas del Zamora & 1867 & $\begin{array}{l}\text { Fuente: El periodismo lojano } \\
\text { (Máximo Agustín Rodríguez, } \\
1948)\end{array}$ \\
\hline La Flor del Zamora & $10 / 1 / 1885$ & $\begin{array}{l}\text { Localización: BEAEP. Número } \\
\text { encontrado: 10/1/1885, mensual. }\end{array}$ \\
\hline La Abeja & 1887 & $\begin{array}{l}\text { Localización: BEAEP. Número } \\
\text { encontrado: mensual }\end{array}$ \\
\hline La Flor Andina & 1889 & Localización: BEAEP. \\
\hline El Principiante & 1890 & Localización: BEAEP. \\
\hline Hojitas Blanquinegras & 1892 & $\begin{array}{l}\text { Fuente: El periodismo lojano } \\
\text { (Máximo Agustín Rodríguez, } \\
1948)\end{array}$ \\
\hline El Porvenir & 1892 & $\begin{array}{l}\text { Localización: Biblioteca Carlos } \\
\text { A. Rolando (Biblioteca Munic. } \\
\text { Guayaquil).Número encon- } \\
\text { trado: 9, 1 de marzo de 1893, } \\
\text { quincenal. }\end{array}$ \\
\hline El Nuevo Horizonte & $\begin{array}{l}\text { Localización: BEAEP. Número } \\
\text { encontrado: 1, 1 de diciembre } \\
\text { de 1895. }\end{array}$ \\
\hline
\end{tabular}




\section{Los autores.}

María Luján González Portea es licenciada y doctora en Ciencias de la Información por la Universidad Complutense de Madrid. Además de en historia del periodismo ecuatoriano, investiga en ética y deontología periodística de los países andinos y en el aprendizaje a distancia. Es profesora titular en la carrera de Comunicación Social en modalidad a distancia y presencial en la Universidad Técnica Particular de Loja (Ecuador).

Rodica Nathali Moreira Ortega es Licenciada en Comunicación Social por la Universidad Técnica Particular de Loja (Ecuador). Se graduó con la tesis: "Estado y levantamiento de las fuentes de la historia de la Comunicación Social de Loja, Zamora y El Oro en el período 1856-1925".

Antonio Checa Godoy es licenciado y doctor en Ciencias de la Información por la Universidad Complutense de Madrid. Prolífico investigador de Historia del Periodismo de España e Iberoamérica y de Historia de la Publicidad. Autor de 24 libros, un centenar de artículos científicos y capítulos de libros. Actualmente es el Decano de la Facultad de Comunicación Social de la Universidad de Sevilla. 